\title{
Fine needle aspiration cytology guided by ultrasound in the diagnosis of subcentimetre thyroid nodules
}

\author{
Cheng $\mathrm{Li}^{1}$, Weiwei Zhan ${ }^{2 *}$, Fang Yi ${ }^{2}$, Bin Zheng ${ }^{1}$, Yaqin Zhou ${ }^{1}$, Ran Zhao ${ }^{1}$ and Yi Jia ${ }^{2}$
}

\begin{abstract}
Background: This study aimed to investigate the value of fine needle aspiration biopsy (FNAB) under ultrasound guidance in diagnosis of thyroid nodules. In a retrospective analysis of FNAB in 1050 cases of patients with 1100 nodules, patients were divided according to the maximum diameter of their nodules into two groups: $>1.0$ and $\leq 1.0 \mathrm{~cm}$. The ultrasound-guided FNAB cytology results were compared between two groups.

Results: Ultrasound findings showed that among 1100 thyroid nodules, 547 were highly suspicious, 358 were moderately, 175 were low, and 19 were very low. Cytology results showed papillary carcinomas in 453, possible papillary cancer in 126 cases, follicular tumors in 26, suspicious follicular tumors in 6, atypical cells in 7, nodular goiter in 289, colloid in 13 , chronic lymphocytic thyroiditis in 175 , and undiagnosed specimen in 5 . Ultrasound diagnosis of thyroid nodules had an overall sensitivity of $86.0 \%$, and a specificity of $81.9 \%$. In nodules larger than $1.0 \mathrm{~cm}$, the sensitivity was $92.8 \%$, and the specificity $92.3 \%$. In nodules $\leq 1.0 \mathrm{~cm}$, the sensitivity was $82.4 \%$, and the specificity was $81.7 \%$.
\end{abstract}

Conclusions: Patients with highly suspicious thyroid nodules on ultrasonography, regardless of nodule sizes, should receive ultrasound-guided FNAB to confirm their natures and direct clinical managements.

Keywords: Thyroid nodules, Ultrasonography, Ultrasound-guided fine-needle aspiration biopsy, Cytology

\section{Background}

With the improved resolution of high frequency ultrasound and new technologies, the detection rate of thyroid nodules has improved significantly, but it is still necessary to use ultrasound-guided fine-needle aspiration biopsy (US-FNAB) to determine the nature of thyroid nodules (Singh Ospina et al. 2016; Kaliszewski et al. 2016). US-FNAB has many advantages, such as real-time guidance, simple operation, safe, few contraindications and complications, and an effective method to identify the benign and malignant thyroid nodules (Cooper et al. 2009; Moon et al. 2012; Kim et al. 2009a, b; Lee et al. 2011). This study was a retrospective analysis of 1050 patients with a total of 1100 thyroid nodules, which were divided into two groups of the maximum diameter over

\footnotetext{
*Correspondence: zhanweiweidoc@163.com

${ }^{2}$ Department of Ultrasound, Ruijin Hospital, Shanghai Jiaotong University School of Medicine, Shanghai, China

Full list of author information is available at the end of the article
}

$1.0 \mathrm{~cm}$ and less than or equaling to $1.0 \mathrm{~cm}$, Ultrasound and cytology were adopted to analyze the value of USFNAB in the diagnosis of thyroid nodules.

\section{Methods \\ Study design}

US-FNAB results of patients with thyroid nodules from January 2013 to December 2013 were retrospectively analyzed. In 2013, there were more than 40,000 patients underwent thyroid ultrasound in Department of Ultrasound of Ruijin Hospital. Among them, there are 5000 thyroid patients received US-FNAB, and about 4000 patients received surgical interventions. Inclusion criteria were as follows: 1 . patients receiving thyroid ultrasound in our hospital; 2. nodules with cytological results; 3. nodules suspicions for malignancy confirmed by surgical pathology; 4. negative cytological nodules confirmed by follow-ups for more than 1 year with unchanged ultrasound appearances or by surgical pathology (Frates et al. 
2005). A total of 1050 cases of patients (298 males and 752 females) with a mean age of $46.0 \pm 13.5$ years old (range 16-84 years old). A total of 1100 thyroid nodules were divided into two groups with the maximum diameter over $1.0 \mathrm{~cm}$ and the maximum diameter less than or equaling to $1.0 \mathrm{~cm}$.

\section{Instruments and methods}

A SIEMENS S2000 using color ultrasound scanner with an ACUSON-18L6HD UHF probe was adopted and the instrument was adjusted to the best image quality. Every patient lay in a supine position with a thin pillow under the shoulders, and the neck extended. A comprehensive thyroid scan was performed to detect any nodule and images were stored.

\section{Ultrasound thyroid nodules and classification criteria}

The number, location, size, shape, aspect ratio, margin, ultrasound halo, internal structure, calcifications, posterior echo, and the extent and pattern of the blood supply of nodules were evaluated. The thyroid nodules and differentiated thyroid cancer treatment guidelines released by American Thyroid Association (ATA) in 2014 based on ultrasound characteristics to predict risks of malignancy. The guideline considered sonographic features of malignant nodules as hypoechoic texture with irregular margins (such as surrounding infiltration and small projections), microcalcifications, vertical growth, and nodular or partial annular calcification. Based on these features, thyroid nodules were divided into high, moderate, low, and very low degrees of suspicion, and benign ones. High suspicion referred to solid hypoechoic nodules or a solid hypoechoic nodule with a cystic component, and the combination of the following characteristics: irregular edges (such as invasion of the surrounding tissue), microcalcifications, vertical growth, nodular or partial annular calcification with destruction zone, hypoechoic soft tissue protrusion, invasion into surrounding thyroid. Moderate suspicion referred to hypoechoic solid nodules with smooth margins, no microcalcifications, no invasion, and vertical growth. Low suspicion referred to hyperechoic nodules or cystic nodules, solid areas, uniform texture, no microcalcifications, regular margins, no extracapsular spread, and non-vertical orientation. Very low suspicion referred sponge-like nodules or partially cystic nodules, not associated with low, medium and high suspicion in any one of sonographic features. Benign ones referred to purely cystic nodules (Brito et al. 2014; Horvath et al. 2009; Ito et al. 2007; Tae et al. 2007).

In this study, images were retrospectively analyzed by two double-blinded Sonologists to determine the classification according to the 2014 ATA guidelines. They were classified as high, moderate, low, and very low suspicion and benign. If there was disagreement in the classification, the final classification should be reached by consensus.

\section{US-FNAB material}

The materials consisted of $5 \mathrm{ml}$ disposable plastic syringes, 27G syringe needles, gloves, iodine swabs, $1 \%$ lidocaine, slides, bottles and ethanol fixed fast staining solution.

\section{US-FNAB specimen collection}

Preoperative coagulation function and body condition of all patients were assessed. Informed consent was obtained. After routine disinfection, sterile towels were applied, and lidocaine was injected for local anesthesia to the thyroid capsule under ultrasound guidance. Under ultrasound-guidance, specimens were collected by aspirated into $5 \mathrm{ml}$ plastic syringes. Thyroid specimens were collected 2-6 times, according to the specific circumstances of each case.

\section{Standard thyroid nodule cytology specimens}

There was an on site cytologist in the cell room next to the ultrasound examination room. By using the "Thyroid Cytopathology Bethesda reporting system (Cibas and Ali 2009): definitions, standards and notes", the specimens were divided into six categories: I: specimen cannot be diagnosed or was unsatisfactory, II: benign, III: equivocal lesions (atypical cells or follicular lesions), IV: follicular neoplasm or suspicious follicular tumors, V: suspicious for malignancy, VI: malignancy. According to the 2010 AACE/AME/ETA "European thyroid nodule diagnosis and treatment guidelines", Bethesda categories I to IV were classified as "negative cytology", while categories V and VI were classified as "positive cytology".

\section{Statistical analysis}

In results of US-FNAB cytology, surgical pathology and ultrasound follow-up of more than 1 year, data were analyzed by using SPSS version 19.0 statistical software. t-test was used to compare the cytological categories between two groups, and numerical data were compared with $\chi^{2}$ test, while consistency of paired data was analyzed with Kappa test.

\section{Results}

In the 1050 patients, a total of 1100 nodules of maximum diameters from 0.29 to $2.8 \mathrm{~cm}$ with an average diameter of $1.08 \pm 0.53 \mathrm{~cm}$ were found. There were 322 nodules larger than $1.0 \mathrm{~cm}$ and 778 of $1 \mathrm{~cm}$ or smaller (amongst which 292 cases were smaller than $0.5 \mathrm{~cm}$ ). Cytological results showed benign in 521 nodules (confirmed by 
surgery in 23, and by follow-ups for more than 1 year in 493). Cytological results were malignant in 579 nodules, confirmed by surgery. Cytological results were satisfactory in 1095 (99.55 \%) cases and non-diagnostic or unsatisfactory in $5(0.45 \%)$, all of which were $0.6 \mathrm{~cm}$ or smaller and were managed by follow-ups.

\section{Thyroid nodule ultrasound results}

The 2014 ATA guidelines recommend dividing thyroid nodules into five categories based on ultrasonographic features, which were high, moderate, low, very low level of suspicion of malignancy, and benign. Results showed benign in one nodule $(0.1 \%)$; very low level of suspicion in 19 nodules (1.7\%); low level of suspicion in 175 nodules (15.9\%); moderate level of suspicion in 358 nodules (32.5\%); and high level of suspicion in 547 nodules (49.7\%). Among nodules smaller than $1.0 \mathrm{~cm}$, results showed benign in 0 nodules $(0 \%)$; very low level of suspicion in 8 nodules $(1 \%)$; low level of suspicion in 98 nodules (12.6\%); moderate level of suspicion in 254 nodules (32.6\%); and high level of suspicion in 418 nodules (53.7\%). Among those larger than $1.0 \mathrm{~cm}$, results showed benign in 1 nodule $(0.3 \%)$; very low level of suspicion in 11 nodules (3.4\%); low level of suspicion in 77 nodules (23.9\%); moderate level of suspicion in 104 nodules (32.3\%); and high level of suspicion in 129 nodules (40.1\%).

\section{US-FNAB cytology results}

The overall US-FNAB cytology results are shown in Table 1. US-FNAB cytopathological results of this study, and the results according to nodule sizes are shown in Table 2.

\section{Ultrasound compared with US-FNAB cytology results}

The relationship between ultrasound features of nodules and US-FNAB cytopathological is presented in Table 3. The relationship between ultrasound features by nodule sizes and US-FNAB cytology is presented in Table 4, while the effects of the patient's gender and

Table 1 Bethesda cytology of thyroid nodules

\begin{tabular}{lcc}
\hline Cytology pathology & Nodules & Ratio (\%) \\
\hline I & 5 & 0.5 \\
II & 477 & 43.4 \\
III & 7 & 0.6 \\
IV & 32 & 2.9 \\
V & 126 & 11.5 \\
VI & 453 & 41.2 \\
Total & 1100 & 100.0 \\
\hline
\end{tabular}

Table 2 US-FNAB cytology pathology Bethesda results by nodule size

\begin{tabular}{lllllllr}
\hline Nodule size & I & II & III & IV & V & VI & Total \\
\hline Maximum diameter $\leq 1.0 \mathrm{~cm}$ & 3 & 311 & 6 & 20 & 95 & 343 & 778 \\
Maximum diameter $>1.0 \mathrm{~cm}$ & 2 & 166 & 1 & 12 & 31 & 110 & 322 \\
Total & 5 & 477 & 7 & 32 & 126 & 453 & 1100 \\
\hline $\mathrm{X}^{2}=15.900, \mathrm{p}=0.007$ & & & & & & &
\end{tabular}

Table 3 Ultrasound findings vs US-FNAB cytology Results

\begin{tabular}{lccr}
\hline Ultrasound & Negative & Positive & Total \\
\hline Benign & 1 & 0 & 1 \\
Very low suspicion & 18 & 1 & 19 \\
Low suspicion & 133 & 42 & 175 \\
Moderate suspicion & 296 & 62 & 358 \\
High suspicion & 73 & 474 & 547 \\
Total & 521 & 579 & 1100 \\
\hline
\end{tabular}

Table 4 US-FNAB cytology results by lesion size

\begin{tabular}{|c|c|c|c|}
\hline & Ultrasound & Negative & Positive \\
\hline \multirow{6}{*}{$\begin{array}{l}\text { Maximum diameter } \\
\leq 1.0 \mathrm{~cm}^{\mathrm{a}}\end{array}$} & Benign & 1 & 0 \\
\hline & Very low suspicion & 7 & 1 \\
\hline & Low suspicion & 69 & 29 \\
\hline & Moderate suspicion & 204 & 50 \\
\hline & High suspicion & 60 & 358 \\
\hline & Total & 340 & 438 \\
\hline \multirow{6}{*}{$\begin{array}{l}\text { Maximum diameter } \\
>1.0 \mathrm{~cm}^{\mathrm{b}}\end{array}$} & Benign & 1 & 0 \\
\hline & Very low suspicion & 11 & 0 \\
\hline & Low suspicion & 64 & 13 \\
\hline & Moderate suspicion & 92 & 12 \\
\hline & High suspicion & 13 & 116 \\
\hline & Total & 181 & 141 \\
\hline
\end{tabular}

$\mathrm{x}^{2}=319.369, \mathrm{p}<0.001$

${ }^{b} x^{2}=187.482, p<0.001$

cytopathological results are presented in Table 5 . In this study, the overall sensitivity of ultrasound in diagnosing nodules was $86.0 \%$ and the specificity was $81.9 \%$. The sensitivity for larger nodules was $92.8 \%$, and the specificity was $92.3 \%$, while for smaller nodules the sensitivity was $82.4 \%$, and the specificity was $81.7 \%$.

\section{Discussion}

Thyroid nodules are common abnormalities of the endocrine system. Although the incidence in different regions of the world is different, the overall upward trend is strong (Xu et al. 2015). With the use of high-resolution ultrasound and the introduction of new technologies, 
Table 5 Cytology by gender and nodule size

\begin{tabular}{llrl}
\hline & Pathological diagnosis & Male & Female \\
\hline Maximum diameter $\leq 1.0 \mathrm{~cm}^{\text {a }}$ & Benign & 81 & 259 \\
& Malignant & 128 & 310 \\
& Total & 209 & 569 \\
Maximum diameter $>1.0 \mathrm{~cm}^{\text {b }}{ }^{2}$ & Benign & 47 & 134 \\
& Malignant & 50 & 91 \\
& Total & 97 & 225 \\
Totals & Benign & 128 & 393 \\
& Malignant & 178 & 401 \\
& Total & 306 & 794 \\
\hline
\end{tabular}

${ }^{a} x^{2}=2.841, p=0.092$

${ }^{b} x^{2}=3.394, p=0.065$

c $x^{2}=5.207, p=0.022$

such as elastography, ultrasound has become the first choice for the diagnosis of thyroid nodules (Burch et al. 2016). As shown in a national large-scale study, ultrasound examination of the thyroid revealed nodules in 20-76 \% (Gharib et al. 2010), which was a dramatic increase over the last 10 years. With a prevalence rate of 5-15 \% (Cooper et al. 2009), thyroid cancer has become a common clinical malignancy with an increasing incidence all over the world (Londero et al. 2013; Davies and Welch 2006). The rate of unnecessary thyroid surgery has also increased. US-FNAB is a non-invasive way to discriminate benign thyroid nodules from malignant ones, and can reduce unnecessary diagnostic surgeries.

The 2014 ATA guideline (Horvath et al. 2009; Ito et al. 2007; Tae et al. 2007), relies on sonographic features to predict risks of malignant thyroid nodules, divides them into high, moderate, low, and very low degree of suspicion, and gives the corresponding probability of malignancy. The risk of malignancy in $70-90 \%$ in a thyroid nodule was rated as high suspicion, a risk of malignancy in 10-20\% was rated as moderate suspicion, a risk of malignancy in 5-10\% was rated as low suspicion, a risk of malignancy in $<3 \%$ was rated as very low suspicion, and a risk of malignancy in $<1 \%$ was rated as benign nodules. Results of this study showed that in nodules rated as "high" and "moderate" suspicion, the proportion of thyroid nodules with positive cytological results was similar to the 2014 ATA guidelines. For nodules with "low", and "very low" degrees of suspicion, the rate of positive USFNAB cytological results was significantly higher than that in the guidelines. Management of thyroid nodules depends on the level of suspicion. For nodules with high and moderate suspicion, US-FNAB is recommended, while follow-up is generally recommended for nodules with low degree of suspicion and US-FNAB is not needed unless there is a family history of thyroid cancer, exposure to ionizing radiation or a strong biopsy request from patients. When the level of suspicion is very low, US-FNABs is not needed.

The 2014 ATA guideline stated that US-FNAB was the most reliable method for preliminary diagnosis of thyroid nodules (Cooper et al. 2009). Many literatures (Nayar and Ivanovic 2009; Bongiovanni et al. 2012; Luu et al. 2011; Theoharis et al. 2009) described patients in whom US-FNAB was done in 89-95\% of cases, including $55-74 \%$ cases diagnosed as benign, $2-5 \%$ diagnosed as malignant, and the remaining diagnosed as "indeterminate cytology". The nodules with unsatisfactory biopsies (Moon et al. 2012; Horvath et al. 2009; Chen et al. 2009) mainly include cystic nodules, calcified nodules, nodules with a rich blood supply, and tough nodules difficult to be punctured. Nodules smaller than $6 \mathrm{~mm}$ and benign nodules are likely to yield insufficient amount of cells. The question of how to deal with cases when the cytology is not clear is an active area of research. For cases with indeterminate cytological results, ATA guidelines recommended a repeat biopsy. From the literature of Cooper, a repeat biopsy can confirm the diagnosis in about $75 \%$ of solid nodules (Cooper et al. 2009). In this study, it was able to obtain satisfactory specimens in $99.55 \%$ cases, which was higher than that reported in the literature. In addition to operator's experience, it was suggested that it was not easy to obtain a satisfactory specimen if less than six punctures were made (Kim et al. 2009a).

The relevance of nodule size to the results of US-FNAB has been controversial. The 2006 ATA guidelines recommended US-FNAB for nodules with diameters larger than $1.0 \mathrm{~cm}$, the 2009 edition reduced the size of suspicious nodules to a diameter larger than $0.5 \mathrm{~cm}$, and the 2014 edition was skeptical about the value of biopsy for nodules with diameters less than $1.0 \mathrm{~cm}$. Recommendations for US-FNAB of nodules with diameters larger than $1.0 \mathrm{~cm}$ should be based on the following criteria: findings outside the thyroid such as invasion or lymph node metastasis, the patient's age, and the demands of process (Frates et al. 2005; Mazzaferri and Sipos 2008). However, some scholars (Kim et al. 2009a, b; Baskin and Duick 2006) believed that early diagnosis of thyroid cancer could reduce the recurrence rate and mortality regardless of nodule sizes. Long-term follow-up of small biopsyproven papillary thyroid cancers did not show distant metastases or mortality (Mazzaferri and Sipos 2008), but young patients (younger than 40 years old) were prone to clinical progression, including rapid tumor growth and cervical lymph node metastases. From the histological point of view, the literatures (Nikiforov and Ohori 2012; Ghossein et al. 2007; Morris et al. 2010) on papillary thyroid carcinoma listed a dozen subtypes, some of which carried a poor prognosis with a high recurrence rate, 
and a low tumor-related survival rate. In these cases, the patient's age, tumor size and clinical staging were irrelevant. Therefore, regardless of the size of thyroid nodules, clarifying their nature to guide clinical management still has a great value.

In this study, the results of US-FNAB cytology of thyroid nodules with diameters of $1.0 \mathrm{~cm}$ or smaller was similar to those larger than $1.0 \mathrm{~cm}$. However, in 182 patients younger than 40 years old with highly suspicious thyroid nodules, US-FNAB cytology was positive in 179 (98.4 \%). Thus, for highly suspicious thyroid nodules, especially in patients younger than 40 years old, timely US-FNAB is clinically significant for confirmation of their natures.

However, this study had some limitations. This study was a retrospective study. The majority of patients with benign cytology were followed up, since thyroid cancer develops slowly. A relatively short follow-up of 1 year did not exclude false negative results. Two cases with positive preoperative US-FNAB but negative histology in very small nodules were excluded.

\section{Conclusions}

Highly suspicious thyroid nodules on ultrasonography, regardless of nodule sizes, should receive US-FNAB to confirm their natures and direct clinical managements.

\section{Abbreviation}

US-FNAB: ultrasound-guided fine-needle aspiration biopsy.

\section{Authors' contributions}

$C L, W W Z, F Y, B Z, Y Q Z, R Z$ and $Y J$ conducted the experiment, collected the data and analyzed the data. $C L$ and WWZ designed the study. $C L$ wrote this manuscript. All authors read and approved the final manuscript.

\section{Author details}

${ }^{1}$ Department of Ultrasound, North Branch of Ruijin Hospital, Shanghai Jiaotong University School of Medicine, Shanghai, China. ${ }^{2}$ Department of Ultrasound, Ruijin Hospital, Shanghai Jiaotong University School of Medicine, Shanghai, China.

\section{Acknowledgements}

This study was approved by Shanghai Shen Kang Hospital Development Center of Clinical Science and Technology Innovation Project (ID: SHDC12015912).

\section{Competing interests}

The authors declare that they have no competing interests.

\section{Consent for publication}

Consent to publish has been obtained from the participant to report individual patient data.

\section{Ethics approval and consent to participate}

This study has been approved by the Ethic Committee of North Branch of Ruijin Hospital, Shanghai Jiaotong University School of Medicine, and complying with the Helsinki Declaration. All subjects gave their consent to participate in this study.

Received: 1 March 2016 Accepted: 9 June 2016

Published online: 24 June 2016

\section{References}

Baskin HJ, Duick DS (2006) The endocrinologists'view of ultrasound guidelines for fine needle aspiration. Thyroid 16(3):207-208. doi:10.1089/ thy.2006.16.207

Bongiovanni M, Spitale A, Faquin WC, Mazzucchelli L, Baloch ZW (2012) The Bethesda system for reporting thyroid cytopathology: a meta-analysis. Acta Cytol 56(4):333-339. doi:10.1159/000339959

Brito JP, Gionfriddo MR, Al Nofal A, Boehmer KR, Leppin AL, Reading C, Callstrom M, Elraiyah TA, Prokop LJ, Stan MN, Murad MH, Morris JC, Montori VM (2014) The accuracy of thyroid nodule ultrasound to predict thyroid cancer: systematic review and meta-analysis. J Clin Endocrinol Metab 99(4):1253-1263. doi:10.1210/jc.2013-2928

Burch HB, Burman KD, Cooper DS, Hennessey JV, Vietor NO (2016) A 2015 survey of clinical practice patterns in the management of thyroid nodules. J Clin Endocrinol Metab. jc20161155. doi:10.1210/jc.2016-1155

Chen SJ, Yu SN, Tzeng JE, Chen YT, Chang KY, Cheng KS, Hsiao FT, Wei CK (2009) Characterization of the major histopathological components of thyroid nodules using sonographic textural features for clinical diagnosis and management. Ultrasound Med Biol 35(2):201-208. doi:10.1016/j. ultrasmedbio.2008.08.017

Cibas ES, Ali SZ (2009) The Bethesda system for reporting thyroid cytopathology. Am J Clin Pathol 132(5):658-665

Cooper DS, Doherty GM, Haugen BR, Kloos RT, Lee SL, Mandel SJ, Mazzaferri EL, Mclver B, Pacini F, Schlumberger M, Sherman SI, Steward DL, Tuttle RM (2009) Revised American Thyroid Association management guidelines for patients with thyroid nodules and differentiated thyroid cancer. Thyroid 19(11):1167-1214. doi:10.1089/thy.2009.0110

Davies L, Welch HG (2006) Increasing incidence of thyroid cancer in the United States, 1973-2002. JAMA 295(18):2164-2167. doi:10.1001/ jama.295.18.2164

Frates MC, Benson CB, Charboneau JW, Cibas ES, Clark OH, Coleman BG, Cronan JJ, Doubilet PM, Evans DB, Goellner JR, Hay ID, Hertzberg BS, Intenzo CM, Jeffrey RB, Langer JE, Larsen PR, Mandel SJ, Middleton WD, Reading CC, Sherman SI, Tessler FN (2005) Management of thyroid nodules detected at US Society of Radiologists in Ultrasound consensus conference statement. Radiology 237(3):794-800. doi:10.1148/ radiol.2373050220

Gharib H, Papini E, Paschke R, Duick DS, Valcavi R, Hegedus L, Vitti P (2010) American Association of Clinical Endocrinologists, Associazione Medici Endocrinologi, and EuropeanThyroid Association medical guidelines for clinical practice for the diagnosis and management of thyroid nodules. Endocr Pract 16(Suppl 1):1-43. doi:10.4158/10024.gl

Ghossein RA, Leboeuf R, Patel KN, Rivera M, Katabi N, Carlson DL, Tallini G, Shaha A, Singh B, Tuttle RM (2007) Tall cell variant of papillary thyroid carcinoma without extrathyroid extension: biologic behavior and clinical implications. Thyroid 17(7):655-661. doi:10.1089/thy.2007.0061

Horvath E, Majlis S, Rossi R, Franco C, Niedmann JP, Castro A, Dominguez M (2009) An ultrasonogram reporting system for thyroid nodules stratifying cancer risk for clinical management. J Clin Endocrinol Metab 94(5):17481751. doi:10.1210/jc.2008-1724

Ito Y, Amino N, Yokozawa T, Ota H, Ohshita M, Murata N, Morita S, Kobayashi K, Miyauchi A (2007) Ultrasonographic evaluation of thyroid nodules in 900 patients: comparison among ultrasonographic, cytological, and histological findings. Thyroid 17(12):1269-1276. doi:10.1089/thy.2007.0014

Kaliszewski K, Zubkiewicz-Kucharska A, Wojtczak B, Strutynska-Karpinska M, Zaleska-Dorobisz U, Leskow E (2016) Ultrasound guided fine-needle aspiration biopsy of thyroid nodules: Does radiologist assistance decrease the rate of unsatisfactory biopsies? Adv Clin Exp Med 25(1):93-100. doi:10.17219/acem/60084

Kim DW, Lee EJ, Kim SH, Kim TH, Lee SH, Kim DH, Rho MH (2009a) Ultrasoundguided fine-needle aspiration biopsy of thyroid nodules: comparison in efficacy according to nodule size. Thyroid 19(1):27-31. doi:10.1089/ thy.2008.0106

Kim DW, Park AW, Lee EJ, Choo HJ, Kim SH, Lee SH, Eom JW (2009b) Ultrasound-guided fine-needle aspiration biopsy of thyroid nodules smaller than $5 \mathrm{~mm}$ in the maximum diameter: assessment of efficacy and pathological findings. Korean J Radiol 10(5):435-440. doi:10.3348/ kj.2009.10.5.435

Lee MJ, Hong SW, Chung WY, Kwak JY, Kim MJ, Kim EK (2011) Cytological results of ultrasound-guided fine-needle aspiration cytology for thyroid 
nodules: emphasis on correlation with sonographic findings. Yonsei Med J 52(5):838-844. doi:10.3349/ymj.2011.52.5.838

Londero SC, Krogdahl A, Bastholt L, Overgaard J, Trolle W, Pedersen HB, Bentzen J, Schytte S, Christiansen P, Godballe C (2013) Papillary thyroid microcarcinoma in Denmark 1996-2008: a national study of epidemiology and clinical significance. Thyroid 23(9):1159-1164. doi:10.1089/ thy.2012.0595

Luu MH, Fischer AH, Pisharodi L, Owens CL (2011) Improved preoperative definitive diagnosis of papillary thyroid carcinoma in FNAs prepared with both ThinPrep and conventional smears compared with FNAs prepared with ThinPrep alone. Cancer Cytopathol 119(1):68-73. doi:10.1002/ cncy.20124

Mazzaferri EL, Sipos J (2008) Should all patients with subcentimeter thyroid nodules undergo fine-needle aspiration biopsy and preoperative neck ultrasonography to define the extent of tumor invasion? Thyroid 18(6):597-602. doi:10.1089/thy.2008.0100

Moon HJ, Son E, Kim EK, Yoon JH, Kwak JY (2012) The diagnostic values of ultrasound and ultrasound-guided fine needle aspiration in subcentimeter-sized thyroid nodules. Ann Surg Oncol 19(1):52-59. doi:10.1245/ s10434-011-1813-1

Morris LG, Shaha AR, Tuttle RM, Sikora AG, Ganly I (2010) Tall-cell variant of papillary thyroid carcinoma: a matched-pair analysis of survival. Thyroid 20(2):153-158. doi:10.1089/thy.2009.0352

Nayar R, Ivanovic M (2009) The indeterminate thyroid fine-needle aspiration: experience from an academic center using terminology similar to that proposed in the 2007 National Cancer Institute Thyroid Fine Needle
Aspiration State of the Science Conference. Cancer 117(3):195-202. doi:10.1002/cncy.20029

Nikiforov YE, Ohori NP (2012) Papillary Carcinoma. In: Nikiforov YE, Biddinger PW, Thompson LDR (eds) Diagnostic pathology and molecular genetics of the thyroid. Lippincott, Philadelphia, pp 263-284

Singh Ospina N, Brito JP, Maraka S, Espinosa de Ycaza AE, Rodriguez-Gutierrez R, Gionfriddo MR, Castaneda-Guarderas A, Benkhadra K, Al Nofal A, Erwin P, Morris JC, Castro MR, Montori VM (2016) Diagnostic accuracy of ultrasoundguided fine needle aspiration biopsy for thyroid malignancy: systematic review and meta-analysis. Endocrine. doi:10.1007/s12020-016-0921-x

Tae HJ, Lim DJ, Baek KH, Park WC, Lee YS, Choi JE, Lee JM, Kang MI, Cha BY, Son HY, Lee KW, Kang SK (2007) Diagnostic value of ultrasonography to distinguish between benign and malignant lesions in the management of thyroid nodules. Thyroid 17(5):461-466. doi:10.1089/thy.2006.0337

Theoharis CG, Schofield KM, Hammers L, Udelsman R, Chhieng DC (2009) The Bethesda thyroid fine-needle aspiration classification system: year 1 at an academic institution. Thyroid 19(11):1215-1223. doi:10.1089/ thy.2009.0155

Xu W, Chen Z, Li N, Liu H, Huo L, Huang Y, Jin X, Deng J, Zhu S, Zhang S, Yu $Y$ (2015) Relationship of anthropometric measurements to thyroid nodules in a Chinese population. BMJ Open 5(12):e008452. doi:10.1136/ bmjopen-2015-008452

\section{Submit your manuscript to a SpringerOpen ${ }^{\circ}$ journal and benefit from:}

- Convenient online submission

- Rigorous peer review

- Immediate publication on acceptance

- Open access: articles freely available online

- High visibility within the field

- Retaining the copyright to your article 